\title{
Correction to: Effects of ecoregional vulnerability on habitat suitability of invasive alien plants: an assessment using 13 species on a global scale
}

\author{
Ji-Zhong Wan ${ }^{1} \cdot$ Zhi-Xiang Zhang $^{3} \cdot$ Chun-Jing Wang ${ }^{1,2}$
}

Published online: 9 April 2019

○) Springer-Verlag GmbH Germany, part of Springer Nature 2019 https://doi.org/10.1007/s12665-019-8186-3

Unfortunately, in the original publication of the article, the Acknowledgement Section was missed. The Acknowledgements Section is given below.

Acknowledgements This work has been supported by the National Natural Science Foundation of China (NSFC) (nos. 31800449 and 31800464) and the Basic Research Project of Qinghai Province, China (nos. 2019-ZJ-936Q and 2019-ZJ-960Q).

The original article can be found online at https://doi.org/10.1007/ s12665-019-8186-3.

Chun-Jing Wang wangchunjing00@163.com

1 State Key Laboratory of Plateau Ecology and Agriculture, Qinghai University, Xining 810016, China

2 College of Agriculture and Animal Husbandry, Qinghai University, Xining 810016, China

3 School of Nature Conservation, Beijing Forestry University, Beijing 100083, China

Publisher's Note Springer Nature remains neutral with regard to jurisdictional claims in published maps and institutional affiliations'. 